\title{
Araştırma Makalesi/Research Article (Original Paper) \\ Yumurtacı Tavuklarda Yumurta Sarısında Biriken Yağda Çözünen Antioksidanlar (Karotenoid, Vitamin E ve Vitamin A) Üzerine Yaşın Etkisi
}

\author{
Mehmet Reşit KARAGEÇíLi ${ }^{1 *}$ Filiz KARADAŞ $^{1}$
}

\author{
${ }^{1}$ Yüzüncü Y1l Üniversitesi, Ziraat Fakültesi, Zotekni Bölümü, Van \\ *e-posta: resitkaragecili@yyu.edu.tr
}

\begin{abstract}
Özet: Bu çalışmada, yumurta tavuğu rasyonlarının toplam karoten, vitamin A, vitamin E düzeyleri ve bunların hayvan yaşına göre yumurta sarısında birikimlerinin nasıl etkilendiği araştırılmışıtır. Bu amaçla Lohmann yumurtacı tavuk ırkından sirasiyla 33., 43. ve 53. haftalarda, Hy-Line yumurtacı tavuk irkında ise sırasıyla 48., 58. ve 68. haftalarda yumurta sarısı örneği alınmıştır. Yumurta sarısındaki toplam karotenoid içeriği Lohmann ırkı için sırasıyla 19.93, $16.85 \mathrm{ve} 18.14(\mu \mathrm{g} / \mathrm{g})$ olarak bulunmuş iken $(\mathrm{p}<0.05)$ Hy-Line irkında bu değerler sırasıyla 16.72, 17.00 ve $18.32(\mu \mathrm{g} / \mathrm{g})$ olarak bulunmuştur $(\mathrm{p}>0.05)$. Ayrıca yumurta sarısındaki toplam vitamin A içeriği Lohmann ırkı için sırasıyla 3.86, $4.34 \mathrm{ve} 3.44(\mu \mathrm{g} / \mathrm{g})$ iken Hy-Line 1rk1 için sırasıyla 7.64, 3.55 ve $3.45(\mu \mathrm{g} / \mathrm{g})$ olarak bulunmuştur $(\mathrm{p}<0.05)$. Bunlara ilaveten yumurta sarısındaki toplam vitamin E içeriği Lohmann ırkı için sırasıyla 110.55, 111.03 ve $115.85(\mu \mathrm{g} / \mathrm{g})$ iken Hy-Line ırkı için sırasıyla 99.31, 97.89 ve $110.01(\mu \mathrm{g} / \mathrm{g}$ ) olarak bulunmuştur (p>0.05). Sonuç olarak yumurtacı tavukların yaşları arttıkça yumurta büyüklügü̈ de artmakta ve birim hacimde biriken besin madde miktarı azalmakta fakat yemler yeniden formülize edildiği takdirde bu olumsuzluk giderilebilmektedir.
\end{abstract}

Anahtar kelimeler: Karoten, Vitamin A, Vitamin E, Yumurta sarısı, Yumurtacı tavuk

\section{The Effects of Age in Layer on Accumulation of Oil-Soluble Antioxidants (Caroteonids, Vitamin $E$ and Vitamin A) Concentration in The Egg Yolk}

\begin{abstract}
In this study laying hen diet's total carotene, vitamin A and vitamin E levels and their effects with hens age how affected their accumulation in egg yolk were investigated. For this aim, egg yolk samples were obtained from Lohmann layers in $33^{\text {rd }}, 43^{\text {rd }}$ and $53^{\text {rd }}$ weeks and Hy-Line layers in $48^{\text {th }}, 58^{\text {th }}$ and $68^{\text {th }}$ weeks respectively. Egg yolk's total carotenoid content was measured as $19.93,16.85$ and 18.14 $\left(\mu \mathrm{g} \mathrm{g}^{-1}\right)$ for Lohmann $(\mathrm{p}<0.05)$ and 16.72, 17.00, and $18.32\left(\mu \mathrm{g} \mathrm{g}^{-1}\right)$ for Hy-Line respectively $(\mathrm{p}>0.05)$. Furthermore egg yolk's total vitamin A content was measured 3.86, 4.34 and $3.44\left(\mu \mathrm{g} \mathrm{g}^{-1}\right)$ for Lohmann and 7.64, 3.55 and $3.45\left(\mu \mathrm{g} \mathrm{g}^{-1}\right)$ for Hy-Line respectively $(\mathrm{p}<0.05)$. In addition to these egg yolk's total vitamin E content was measured as 110.55, 111.03 and $115.86\left(\mu \mathrm{g} \mathrm{g}^{-1}\right)$ for Lohmann and 99.31, 97.89 and $110.01\left(\mu \mathrm{g} \mathrm{g}^{-1}\right)$ for Hy-Line respectively $(\mathrm{p}>0.05)$. As a result layers got old their egg size increase and nutrients in per unit volume decreased but this drawback could be compensated by reformulating diet formulations.
\end{abstract}

Key words: Carotene, Vitamin A, Vitamin E, Egg yolk, Laying hen

\section{Giriş}

İnsan vücudunun gereksinim duyduğu hemen hemen tüm besin maddelerini en uygun miktar ve oranda içeren yumurta, dengeli insan beslenmesi için üzerinde durulması gereken önemli hayvansal gıda kaynaklarından birisidir (Çelebi ve Karaca 2006). Yumurta sarısının rengi tüketiciler için önemli bir husustur ve onların satın alma davranışlarını etkilemektedir (De-Groote 1970; Fletcher 1999). Karotenler (Gürbüz ve ark. 2004) ve ksantofiller, yumurta sarısında ve broiler derisinde istenen rengi elde etmek amacıyla yıllardır kanatlı rasyonlarda kullanılmaktadır. Yemlere \% 0.021 düzeyinde sentetik kantaksaktin takviyesinin yumurta üretimini ve yumurta sarısının pigment düzeyini artırabileceği düşünülmektedir (Cho ve ark. 2013). Yumurta sarısının rengi karotenoidlerin yumurta sarısında depolanmasına, rasyondaki karotenoidlerin dayanıklılığına, renklendirme kapasitesine ve kalitesine bağlıdır (Gürbüz ve ark. 2004). Endüstriyel olarak kullanılan yüksek enerjili yemler düşük pigmentlidir. Bundan dolayı bu yemler 
pigment ile takviye edilmelidir (Vargas ve ark. 1998). Tüketicilerin tercih ettiği yumurta sarısı ve deri rengi, yemlerdeki doğal renk maddeleri (mısırdaki karotinoidler, yeşil bitkiler, kırmızı kuru biber, çeşitli çiçekler) ve yemlere katılan sentetik maddeler ile sağlanabilmektedir (Jeroch ve ark. 1993). Sentetik karotenoidlerin 1960'lı yılların sonlarına doğru gelişmesiyle 1970'li yıllarda kanatlı endüstrisi tarafından geniş çaplı yararlanıldığından yumurta sarısıyla ilgili doğal alternatif çalışmalar azalmıştır. Ancak son zamanlarda tüketicilerin gıdalarda ve yemlerde sentetik katkı kullanımı ile ilgili kaygıların artması üzerine doğal yem katkı maddelerine ilgi artmıştır (Karadas ve ark. 2006). Ayrıca sağlık üzerindeki potansiyel etkisi sebebiyle lutein (Møller ve ark. 2000; Johnson 2002) ve likopen (Agarwal ve Rao 2000; Porrini ve Riso 2000; Rao ve Agarwal 2000) gibi doğal pigmentler bakımından zenginleştirilmiş ürünlere talebi arttırmıştır. Vitamin A ve vitamin E kanatlı beslemede önemli bir role sahiptir. Yumurtacı tavuklarda diyet içine yağda çözülebilen vitaminlerin yüksek düzeyde katılmasıyla bu vitaminlerin yumurta sarısındaki komposizyonları artmaktadır (Jiang ve ark. 1994; Surai ve ark. 1995). Civcivlerde bağışıklık kabiliyeti, diyetlere NRC (1994) tarafından ön görülen vitamin A düzeyinden daha fazla vitamin A eklenmesiyle artabileceği düşünülmektedir (Sklan ve ark. 1994). Buna karşllık tolere edilebilir üst sınırın aşılması durumunda, aşırı vitamin A alınımı toksisiteye neden olabilmektedir (Veltmann ve Jensen 1986). Surai ve ark. (1998) tarafından yapılan çalışmada diyetteki vitamin A düzeyinin artmasıyla yumurta sarısındaki vitamin A konsantrasyonun da artığı bildirilmiştir. Diğer taraftan aynı çalışmada diyetteki vitamin A seviyesinin artmasıyla yumurta sarısındaki vitamin E ve karoten konsantrasyonun baskılandığı ve düzeyinin düştüğü bildirilmiştir.

Karadas ve ark. (2006) yapmış oldukları bir çalışmada damızlık bıldırcınların yemlerine marigold ekstraktı, domates tozu ve yonca konsantresi (Px-Agro) ilavesi ile beslenen damızlık bıldırcınların yumurta sarısındaki lutein, zeaksantin, likopen ve $\beta$-karoten konsantrasyonlarında bir artış olduğunu, fakat $\alpha$-tokoferol ve $\gamma$-tokoferol birikiminin bu muamelelerden etkilenmediğini bildirmişlerdir. Bir başka çalışmada Tagetes erectus and Capsicum sp. elde edilen kırmızı ve sarı ksantofil karışımının sentetik sitranaksantin, kantaksantin ve apoester-8-karotenoid etil ester pigmentlerinin etkinliği karşılaştırılmıştır (Santos-Bocanegra ve ark. 2004). Bu çalışmada hiçbir muamelenin yem tüketimi, yem değerlendirme ve yumurta üretimine etkisi olmadığı halde pigment ve karoten konsantrasyonu kullanılan gruplarda yumurta sarısı renginin önemli ölçüde değiştĭgi sonucuna varmışlardır. Hasin ve ark. (2006) yaptıkları farklı bir çalışmada marigold ve portakal ekstraktının yumurta üretimi, iç ve dış yumurta kalitesi üzerine zararlı bir etkisinin olmadığını dahası marigoldun daha etkin bir yumurta sarısı elde etmek için kullanılabileceğini bildirmişlerdir. Paprika (kırmızıbiber) özünün buğday temelli rasyonlara ilavesi ile yapılan çalışmada paprika özü ilavesinin yumurta sarısındaki kolesterol üzerine herhangi bir etkisinin bulunmadığı saptanmıştır. Diğer taraftan yumurta sarısındaki karotenoid birikimi ile rasyona ilave edilen kırmızıbiber özü arasında pozitif bir ilişki gözlenmiştir (Niu ve ark. 2008).

Görüldüğ̈̈ üzere yumurtanın kalite ve besin içeriği son yıllarda artan bir ilgi görmektedir. Bu nedenle bu çalışmada; ticari yumurta tavuğu rasyonlarının karoten düzeyi ve bunun tavuğun yaşına göre yumurta sarıs pigment düzeyini etkileyip etkilemeyeceği, buna ilaveten diğer yağda çözünen vitamin A ve vitamin E'nin bundan nasıl etkilendiği iki farklı tavuk ırkında ve farklı haftalarda araştırılması amaçlanmıştır.

\section{Materyal ve Yöntem}

Denemede kullanılan yumurta ve yem örnekleri Van ilinde bulunan ticari yumurta tavukçuluğu yapan bir işletmeden temin edilmiştir. Bu çalışmada Hy-Line ve Lohmann yumurtacı tavuk 1rkı, iki farklı genotip olarak seçilmiştir. Hy-Line yumurtacı tavuk ırkı için 48., 58. ve 68. haftalık yaşlarda, Lohmann yumurtacı tavuk ırk1 için 33., 43. ve 53. haftalık yaşlarda kümeslerden rastgele 10 adet yumurtanın seçilmesi ile bu haftalarda tavuklara verilen yemlerden örnekler alınarak deneme yürütülmüştür.

Deneme süresince Lohmann ve Hy-Line yumurtacı tavuk ırklarına farklı yaşlarda verilen yemlerin toplam karotenoid içeriği Çizelge 1'de, toplam vitamin E içeriği Çizelge 2'de ve toplam vitamin A içeriği de Çizelge 3’te verilmiştir. 


\section{R. KARAGEÇİLI, F. KARADAŞ}

Çizelge 1. Lohmann ve Hy-Line yumurtacı tavuk ırklarına farklı yaşlarda verilen yemlerdeki ortalama toplam karotenoid değerleri ve standart hataları $(\mu \mathrm{g} / \mathrm{g})$

\begin{tabular}{lccc}
\hline Irk & \multicolumn{3}{c}{ Yaş } \\
\hline \multirow{2}{*}{ Lohmann } & 33. Hafta & 43. Hafta & 53. Hafta \\
\cline { 2 - 4 } & $5.137 \pm 0.700^{\mathrm{b}}$ & $7.504 \pm 1.162^{\mathrm{ab}}$ & $9.364 \pm 0.859^{\mathrm{a}}$ \\
\hline \multirow{2}{*}{ Hy-Line } & 48. Hafta & Yaş & 68. Hafta \\
\cline { 2 - 4 } & $5.292 \pm 0.446^{\mathrm{b}}$ & $6.557 \pm 0.329^{\mathrm{b}}$ & $9.854 \pm 0.759^{\mathrm{a}}$ \\
\hline
\end{tabular}

ab Aynı satırdaki farklı harfler istatistik bakımdan önemlidir $(\mathrm{p}<0.05)$.

Çizelge 2. Lohmann ve Hy-Line yumurtacı tavuk ırklarına farklı yaşlarda verilen yemlerdeki ortalama toplam vitamin E değerleri ve standart hataları $(\mu \mathrm{g} / \mathrm{g})$

\begin{tabular}{lccc}
\hline Irk & \multicolumn{3}{c}{ Yaş } \\
\hline \multirow{2}{*}{ Lohmann } & 33. Hafta & 43 . Hafta & 53. Hafta \\
\hline & $85.099 \pm 8.025^{\mathrm{b}}$ & $87.661 \pm 12.914^{\mathrm{b}}$ & $140.683 \pm 7.527^{\mathrm{a}}$ \\
\hline \multirow{2}{*}{ Hy-Line } & 48. Hafta & Yaş & 68. Hafta \\
\cline { 2 - 4 } & $96.362 \pm 9.829^{\mathrm{b}}$ & $98.003 \pm 3.117^{\mathrm{b}}$ & $145.494 \pm 5.461^{\mathrm{a}}$ \\
\hline
\end{tabular}

${ }^{\text {ab }}$ Ayn1 satırdaki farklı harfler istatistik bakımdan önemlidir $(\mathrm{p}<0.05)$.

Çizelge 3. Lohmann ve Hy-Line yumurtacı tavuk ırklarına farklı yaşlarda verilen yemlerdeki ortalama toplam vitamin A değerleri ve standart hataları $(\mu \mathrm{g} / \mathrm{g})$

\begin{tabular}{lccc}
\hline Irk & \multicolumn{3}{c}{ Yaş } \\
\hline \multirow{2}{*}{ Lohmann } & 33. Hafta & 43. Hafta & 53. Hafta \\
\cline { 2 - 4 } & $3.961 \pm 0.877^{\mathrm{a}}$ & $0.570 \pm 0.352^{\mathrm{b}}$ & $5.203 \pm 0.699^{\mathrm{a}}$ \\
\hline \multirow{2}{*}{ Hy-Line } & 48 . Hafta & Yaş & 68. Hafta \\
\cline { 2 - 4 } & $1.840 \pm 0.877^{\mathrm{a}}$ & $0.919 \pm 0.231^{\mathrm{b}}$ & $3.316 \pm 0.729^{\mathrm{a}}$ \\
\hline
\end{tabular}

${ }^{\mathrm{ab}}$ Ayn1 satırdaki farklı harfler istatistik bakımdan önemlidir $(\mathrm{p}<0.05)$.

\section{Yöntem}

Yumurta sarısının koyuluğunu belirmede Roche Yolk Color Fan (RYCF) renk skalası kullanılmıştır. Yumurta sarısındaki karotenoid konsatrasyonunun belirlenmesi için yumurtalardan 200-300 mg yumurta sarısı alınıp $0.7 \mathrm{ml} \% 5$ 'lik $\mathrm{NaCl}$ çözeltisiyle karıştırıldıktan sonra üzerlerine $1 \mathrm{ml}$ etanol ilave edilip homojenize edilmiştir. Homojenizasyon işleme sırasında örneklere 2 defa olmak üzere 2 ml heksan eklenmiştir. 10 dakikalık santrifüjden sonra organik madde karışımlı heksan 2 defa toplanıp nitrojen gazı altında uçurulduktan sonra diklormetan/metanol $(1: 1 \mathrm{v} / \mathrm{v})$ çözeltisinde yeniden çözdürülmüş ve HPLC analizi için $10 \mu$ l enjeksiyon yapılmıştır. HPLC kalibrasyonu Lutein (DSM Nutrition Basel-Swetzerland) standartı ile yapılmıştır. Vitamin E $(\alpha-, \gamma-, \delta$ - tokoferoller) ve vitamin A seviyesini belirlemek için Spherisorb ODS 2 tipi, $3 \mu \mathrm{m} \mathrm{C}_{18}$ HPLC kolonu metanol-su (97:3, v/v) mobil fazıyla $1.05 \mathrm{ml} / \mathrm{dk}$ akış oranında kullanılmıştır (Surai ve Speake 1998a;b; Karadas ve ark. 2011). HPLC cihazının kalibrasyonunda kullanılan tokoferol standartları metanol ile hazırlanmıştır.

Yem örneklerinin hazırlanması; örnekten 1 gr alınarak pyrogallol varlığında etanolik KOH ile $30 \mathrm{dk}$ ve 70 ${ }^{\circ} \mathrm{C}$ de sabunlaştırılmıştır. Daha sonra üzerlerine iki defa olmak üzere $5 \mathrm{ml}$ heksan eklenerek $30 \mathrm{dk}$ soğuk ortamda bekletmenin ardından heksan toplanarak nitrojen gazı altında uçurularak kalıntı diklormetanmetanol (1:1 v/v) çözeltisinde tekrar çözdürülmüştür (Surai ve ark. 1996; Karadas ve ark. 2005). Toplam karotenoid, vitamin E ve vitamin A analizleri yumurta sarısındaki ile aynı şekilde HPLC cihazı ile belirlenmiştir.

Elde edilen tüm verilere SAS istatistik programında varyans analizi yapılmış ve her bir ırkın yaşları arasındaki farkın önemli olup olmadığı Duncan testi ile belirlenmiştir (SAS 2002). 


\section{Bulgular ve Tartışma}

Çizelge 1 ve Çizelge 2'den anlaşılacağı üzere yumurtacı tavukların yaşları arttıkça yemleri yeniden formüle edilerek yemde bulunan toplam karotenoid ve vitamin E seviyesinin de arttığı saptanmıştır. Aynı durum vitamin A için söz konusu değildir.

Farklı iki yumurtacı tavuk ırkından alınan yumurtaların RYCF değerleri Çizelge 4'de verilmiştir. Çizelgeden anlaşılacağı üzere Lohmann ırkında 43. ve 53. haftalardaki yumurta sarısı 33. haftadaki yumurta sarısından daha koyu olup, bu renk farklılığının önemli olduğu saptanmıştır $(\mathrm{p}<0.05)$. Benzer durum Hy-Line 1rk1 içinde geçerlidir ve bu ırkın 58. ve 68. haftalardaki yumurta sarısı 48. haftadaki yumurta sarısından daha koyu olup yumurta sarısında görülen bu fark anlamlı bulunmuştur $(\mathrm{p}<0.05)$.

Çizelge 4. Lohmann ve Hy-Line yumurtacı tavuk ırklarının farklı yaşlardaki ortalama RYCF değerleri ve standart hataları

\begin{tabular}{lccc}
\hline Irk & \multicolumn{3}{c}{ Yaş } \\
\hline \multirow{2}{*}{ Lohmann } & 33. Hafta & 43. Hafta & 53. Hafta \\
\cline { 2 - 4 } & $11.05 \pm 0.229^{\mathrm{b}}$ & $12.35 \pm 0.211^{\mathrm{a}}$ & $12.25 \pm 0.200^{\mathrm{a}}$ \\
\hline \multirow{2}{*}{ Hy-Line } & 48. Hafta & Yaş & 68. Hafta \\
\cline { 2 - 4 } & $11.45 \pm 0.117^{\mathrm{b}}$ & $12.35 \pm 0.236^{\mathrm{a}}$ & $12.70 \pm 0.200^{\mathrm{a}}$ \\
\hline
\end{tabular}

ab Aynı satırdaki farklı harfler istatistik bakımdan önemlidir $(\mathrm{p}<0.05)$.

Karadaş ve ark. (2006) yapmış oldukları bir çalışmada da bu sonuçlara benzer farklılıklar görülmüş ve bu durum karoteonid kaynaklarındaki farklılıktan ve tavukların yaşından kaynaklandığı gözlemlenmiştir. Ayrıca, Şamlı ve ark. (2005) bu durumu yumurta sarısı rengi oluşumunda pigment kaynağının niceliğinin yanında niteliğinin de önemli olduğunu bildirdikleri çalışmayla paralellik göstermektedir.

Çizelge 5. Lohmann ve Hy-Line yumurtacı tavuk ırklarının farklı yaşlarda yumurta sarısındaki ortalama toplam karotenoid değerleri ve standart hataları $(\mu \mathrm{g} / \mathrm{g})$

\begin{tabular}{lccc}
\multicolumn{5}{c}{ toplam karotenoid değerleri ve standart hatalar $(\mu \mathrm{g} / \mathrm{g})$} \\
\hline Irk & \multicolumn{3}{c}{ Yaş } \\
\hline \multirow{2}{*}{ Lohmann } & 33. Hafta & 43. Hafta & 53. Hafta \\
\cline { 2 - 4 } & $19.927 \pm 0.787^{\mathrm{a}}$ & $16.846 \pm 0.496^{\mathrm{b}}$ & $18.138 \pm 1.194^{\mathrm{ab}}$ \\
\hline \multirow{2}{*}{ Hy-Line } & 48. Hafta & Yaş & 68. Hafta \\
\cline { 2 - 4 } & $16.717 \pm 0.575$ & $17.002 \pm 0.370$ & $18.318 \pm 0.891$ \\
\hline
\end{tabular}

ab Aynı satırdaki farklı harfler istatistik bakımdan önemlidir $(\mathrm{p}<0.05)$.

Çizelge 5'te Lohmann ve Hy-Line yumurtacı tavuk ırklarının farklı yaşlarda yumurta sarısındaki ortalama toplam karotenoid değerleri verilmiş ve Lohmann ırkı için yumurta sarısındaki toplam karotenoid birikimi 33. haftada en yüksek değerde olup, 43. haftayla olan $3.08 \mu \mathrm{g} / \mathrm{g}$ 'lık fark önemlidir $(\mathrm{p}<0.05)$. Hy-Line ırkında ise yumurta sarısındaki en yüksek toplam karotenoid birikimi 68. haftada gerçekleşmiş olup farkların önemsiz olduğu gözlenmiştir(p>0.05). Skřivan ve Englmaierová (2014) yaptıkları bir çalışmada; yemdeki karotenoid seviyesine bağlı olarak yumurta sarısındaki karotenoid seviyesinin de arttığını belirten araştırmalarıyla elde ettiğimiz bulgulardan Hy-Line ırkının sonuçları ile paralellik gösterdiği ancak Lohmann ırkının sonuçları ile paralellik göstermediği saptanmıştır. Lohmann ırkı tavukların sonuçları; Karadas ve ark.'nın (2006) yemlere farklı karotenoid kaynakları uyguladıkları, yumurta sarısının karotenoid içeriğinin hem karotenoid kaynağındaki farklılık hem de hayvanın yaşına bağlı olarak dalgalanma gösterdiğini belirten araştırmanın sonuçları ile benzerlik göstermektedir. Bu durum Surai ve ark.'nın (2001) yumurtanın karoten düzeyinin yemdeki birçok faktöre ve ince bağırsaktaki emilime bağlı olduğunu bildirdikleri literatürle açıklanabilmektedir. 


\section{R. KARAGEÇİLI, F. KARADAŞ}

Çizelge 6. Lohmann ve Hy-Line yumurtacı tavuk 1rklarına farklı yaşlarda yumurta sarısındaki ortalama toplam vitamin E değerleri ve standart hataları $(\mu \mathrm{g} / \mathrm{g})$

\begin{tabular}{lccc}
\hline \multicolumn{1}{l}{ Irk } & \multicolumn{3}{c}{ Yaş } \\
\hline \multirow{2}{*}{ Lohmann } & 33. Hafta & 43. Hafta & 53. Hafta \\
\cline { 2 - 4 } & $110.549 \pm 6.217$ & $111.029 \pm 6.363$ & $115.854 \pm 8.986$ \\
\hline \multirow{2}{*}{ Hy-Line } & 48. Hafta & Yaș & 68. Hafta \\
\cline { 2 - 4 } & $99.311 \pm 8.197$ & 58. Hafta & $110.008 \pm 6.830$ \\
\hline
\end{tabular}

Lohmann ve Hy-Line yumurtacı tavuk ırklarına farklı yaşlarda yumurta sarısındaki ortalama toplam vitamin E değerleri Çizelge 6'da verilmiştir. Lohmann tavuk ırkında yaş artıkça yumurta sarısında biriken vitamin E seviyesinde artış saptanmasına rağmen bu artışın önemli olmadığı tespit edilmiştir ( $\mathrm{p}>0.05)$. Benzer şekilde Hy-Line tavuk ırkında yumurta sarısında biriken vitamin E seviyesi en yüksek 68. haftada gözlenmiştir. Lohmann ırkında olduğu gibi yaşlar arasındaki farkların önemli olmadığı saptanmıştır ( $>$ >0.05). Loetscher ve ark. (2013); Skřrivan ve Englmaierová (2014) yapmış oldukları çalışmalarda yumurta sarısındaki vitamin $\mathrm{E}$ içeriğinin yemdeki vitamin $\mathrm{E}$ içeriğine paralel bir artış gösterdiğini bildirmişlerdir. Lohmann ırkı tavuklarının sonuçları bu literatürler ile paralellik gösterirken, Hy-Line ırkı tavuklarının sonuçları bu literatürlerle uyum göstermemektedir. $\mathrm{Bu}$ durum vitamin E'nin absorbsiyonunun büyük ölçüde karoten absorbsiyonuna benzerlik göstermesiyle açıklanabilmektedir (Surai 1999).

Çizelge 7. Lohmann ve Hy-Line yumurtacı tavuk ırklarına farklı yaşlarda yumurta sarısındaki ortalama toplam vitamin A değerleri ve standart hataları $(\mu \mathrm{g} / \mathrm{g})$

\begin{tabular}{lccc}
\hline Irk & \multicolumn{3}{c}{ Yaş } \\
\hline \multirow{2}{*}{ Lohmann } & 33. Hafta & 43. Hafta & 53. Hafta \\
\cline { 2 - 4 } & $3.857 \pm 0.280^{\mathrm{b}}$ & $4.344 \pm 0.214^{\mathrm{a}}$ & $3.435 \pm 0.145^{\mathrm{b}}$ \\
\hline \multirow{2}{*}{ Hy-Line } & 48. Hafta & Yaş & 68. Hafta \\
\cline { 2 - 4 } & $7.641 \pm 1.241^{\mathrm{a}}$ & $3.553 \pm 0.209^{\mathrm{b}}$ & $3.451 \pm 0.173^{\mathrm{b}}$ \\
\hline
\end{tabular}

${ }^{\text {ab }}$ Aynı satırdaki farklı harfler istatistik bakımdan önemlidir $(\mathrm{p}<0.05)$.

İki farklı yumurtacı tavuk ırkının farklı yaşlarda yumurta sarısında biriken vitamin A değerleri ortalaması Çizelge 7'de verilmiştir. Yumurta sarısında biriken en yüksek vitamin A seviyesi Lohmann 1rkında 43. haftada gerçekleşirken Hy-Line tavuk ırkında 48. haftada gerçekleşmiş ve anlamlı bulunmuştur $(\mathrm{p}<0.05)$. Bu sonuçlar Surai ve ark. (1998) ve Mendonça ve ark. (2002) tarafindan yapılan, yemlerdeki vitamin A düzeyinin arttıkça yumurta sarısındaki vitamin A düzeyinin de artığının gözlemlendiği çalışmalarla uyum içerisinde olmadığı görülmüştür.

\section{Sonuc}

Yumurtacı tavuklar yedikleri yemlerdeki karotenoidleri yumurta sarısında depolama yeteneğine sahiptir. Yumurtacı tavukların yaşları arttıkça yem tüketimleri artmakta fakat yemden yararlanma oranı düşmekte ve böylelikle hayvansal dokularda biriken besin madde oranı büyük ölçüde aynı kalmaktadır. Bu oran korunurken, diğer yandan yaş arttıkça yumurta ve yumurta sarısı büyüklüğü de artmaktadır. Bundan dolayı birim hacimdeki besin madde miktarını korumak için yemler yeniden formüle edilmektedir. Bu çalışmada yaşa bağlı olarak yemdeki besin madde kompozisyonunun arttırılması ile yumurta sarısında bulunan besin madde içeriğinin büyük ölçüde dengelendiği sonucuna varılmıştır.

Yapmış olduğumuz bu çalışmada elde ettiğimiz diğer bir sonuç ise ticari koşullarda yetiştirilen yumurtacı tavuklardan edinilen yumurta sarısı koyuluğu ile yumurta besleyici özelliğinin arttığı saptanmıştır. 


\section{Teșekkür}

Bu bildiri Norveç'in Stavanger kentinde düzenlenen XIV European Poultry Conference'da poster olarak sunulmuştur.

\section{Kaynak}

Agarwal S, Rao AV (2000). Tomato lycopene and its role in human health and chronic diseases. Canadian Medical Association Journal. 19: 739-744.

Cho JH, Zhang ZF, Kim IH (2013). Effects of canthaxanthin on egg production, egg quality and egg yolk color in laying hens. Journal of Agricultural Science. 5 (1): 269-274. DOI:10.5539/jav.v5n1p269

Çelebi Ş, Karaca H (2006). Yumurtanın besin değeri, kolesterol içeriği ve yumurtayı n-3 yağ asitleri bakımından zenginleştirmeye yönelik çalışmalar. Atatürk Üniv. Zir. Fak. Derg. 37 (2): 257-265.

De-Groote G (1970). Research on egg yolk pigmentation and its practical application. World's Poult. Sci. J. 20: 435-441.

Fletcher DL (1999). Broiler breast meat color variation, pH, and texture. Poultry Science. 78: 1323-1327.

Gürbüz Y, Kamalak A, Çiçek T, Sakarya M (2004). Doğal karotenoid kaynakları ve yumurta sarı rengi. 4. Ulusal Zootekni Bilim Kongresi. 1-4 Eylül, Isparta, Türkiye, ss: 325-330.

Hasin BM, Ferdaus AJM, Islam MA, Uddin MJ, Islam MS (2006). Marigold and orange skin as egg yolk color promoting agents. International Journal of Poultry Science. 5 (10): 979-987.

Jeroch H, Flachowsky G, Weißbach F (1993). Futtermittelkunde, p. 422, Gustav Fischer Verlag Jena, Stuttgart.

Jiang YH, Mcgeachin RB, Bailey CA (1994). $\alpha$-tocopherol, $\beta$-carotene and retinol enrichment of chicken eggs. Poultry Science. 73: 1137-1143.

Johnson EJ (2002). The role of carotenoids in human health. Nutrition in Clinical Care. 5: 56-65.

Karadas F, Grammenidis E, Surai PF, Acamovic T, Sparks NHC (2006). Effects of carotenoids from lucerne, marigold and tomato on egg yolk pigmentation and carotenoid composition. British Poultry Science. 47 (5): 561-566.

Karadas F, Surai PF, Sparks NHC (2011). Changes in broiler chick tissue concentrations of lipid-soluble antioxidants immediately post-hatch. Comparative Biochemistry and Physiology. 160 (Part A): $68-71$.

Karadas F, Surai PF, Sparks NHC, Grammenidis E (2005). Effects of maternal dietary supplementation with three sources of carotenoids on the retinyl esters of egg yolk and developing quail liver. Comparative Biochemistry and Physiology. 140 (Part A): 430-435.

Loetscher Y, Kreuzer M, Messikommer RE (2013). Utility of nettle (Urtica Dioica) in layer diets as a natural yellow colorant for egg yolk. Animal Feed Science and Techonology. 186: 158-168.

Mendonça Jr. CX, Almeida CRM, Mori AV, Watanabe C (2002). Effect of dietary vitamin A on egg yolk retinol and tocopherol levels. The Journal of Applied Poultry Research 11:373-378.

Møller SM, Jacques PF, Blumberg JB (2000). The potential role of dietary xanthophylls in cataract and age-related macular degeneration. Journal of the American College of Nutrition. 19 (5 Suppl.): $522-527$.

Niu Z, Fu J, Gao Y, Liu F (2008). Influence of paprika extract supplement on egg quality of laying hens fed wheat-based diet. International Journal of Poultry Science. 7 (9): 887-889.

Porrini M, Riso P (2000). Lymphocyte lycopene concentration and DNA protection from oxidative damage is increased in women after a shortperiod of tomato consumption. Journal of Nutrition. 130: $189-192$.

Rao AV, Agarwal S (2000). Role of antioxidant lycopene in cancer and heart disease. Journal of the American College of Nutrition. 19: 563-569.

Santos-Bocanegra E, Ospina-Osorio X, Oviedo-Rondón EO (2004). Evaluation of xanthophylls extracted from Tageteserectus (marigold flower) and Capsicum Sp. (red pepper paprika) as a pigment for egg-yolks compare with synthetic pigments. International Journal of Poultry Science. 3 (11): 685-689.

SAS Inc. (2009). SAS for Windows. Version 9.1.3, Cary, NC, USA.

Sklan D, Melamed D, Friedman A (1994). The effect of varying levels of dietary vitamin A on immune response in the chick. Poultry Science. 73: 843-847. 


\section{R. KARAGEÇILİ, F. KARADAŞ}

Skřivan M, Englmaierová M (2014). The deposition of carotenoids and $\alpha$-tocopherol in hen eggs produced under a combination of sequential feding and grazing. Animal Feed Science and Technology. 190: 79-86.

Surai PF (1999). Vitamin E in avian reproduction. Poultry and Avian Biology Reviews. 10: 1-60.

Surai PF, Ionov I, Buzhin A, Buzhina N (1995). Vitamin E and egg quality. In: Proceedings of the 6th European Symposium on the Quality of Egg and Egg Products, Zaragoza, Spain, pp. 387-394.

Surai PF, Ionov IA, Kuklenko TV, Kostjuk IA, Acpherson AM, Speake BK, Noble RC, Sparks NHC (1998). Effect of supplementing the hen's diet with vitamin A on the accumulation of vitamins A and E, ascorbic acid and carotenoids in the egg yolk and in the embryonic liver. British Poultry Science. 39: 257-263.

Surai PF, Noble RC, Speake BK (1996). Tissue-specific differences in antioxidant distribution and susceptibility to lipid peroxidation during development of the chick embryo. Biochimica et Biophysica Acta. 1304: 1-10.

Surai PF, Speake BK (1998a). Selective excretion of yolk-derived tocotrienols into the bile of chick embryo. Comparative Biochemistry and Physiology. 121 (B): 393-396.

Surai PF, Speake BK (1998b). Distribution of carotenoids from the yolk to the tissues of the chick embryo. The Journal of Nutritional Biochemistry. 9: 645-651.

Surai PF, Speake BK, Sparks NHC (2001). Carotenoids in avian nutrition and embryonic development. Absorption, availability and levels in plasma and egg yolk. Journal of Poultry Science. 38: 1-27.

Şamlı HE, Şenköylü N, Akyürek H, Ağma A (2005). Doğal pigmentlerin yaşlı tavuklarda yumurta sarısına etkileri. Journal of Tekirdag Agricultural Faculty. 2 (3): 281-286.

Vargas FD, Lo'pez OP, González EA (1998). Effects of sunlight illumination of marigold flower meals on egg yolk pigmentation. Journal of Agricultural and Food Chemistry. 46: 698-706.

Veltmann JR, Jensen LS (1986). Vitamin A toxicity in the chick and turkey poults. Poultry Science. 65: $538-545$. 